\title{
Co-Supplementation of Dietary Seaweed Powder and Antibacterial Peptides Improves Broiler Growth Performance and Immune Function
}

Euthor(s)

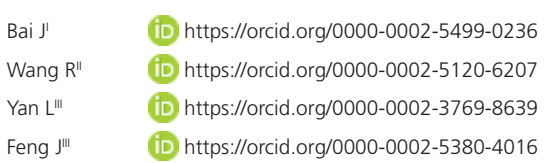

(iD) https://orcid.org/0000-0002-5380-4016

Department of Life Science, Lüliang University, Shanxi 033001, P.R. China.

" College of Animal Husbandry Engineering, Henan Vocational College of Agriculture, Henan 451450, P.R. China.

II College of Agriculture, Shanxi Agricultural University, Shanxi 030801, P.R. China.

\section{Mail Address}

Corresponding author e-mail address Jian Bai

Department of Life Science, Lüliang University, Lüliang, Shanxi 033001, P.R.

China.

Phone: +86 15835826508

Email: bjllxy@llhc.edu.cn

\section{- Keywords}

Broiler; Cecropin; Laminaria japonica powder; Live Performance.

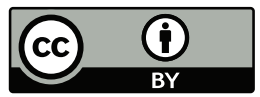

Submitted: 21/October/2018 Approved: 19/February/2019

\section{ABSTRACT}

The feasibility of Laminaria japonica powder (LJP) combined with cecropin as a dietary supplement to enhance broiler growth performance and immune function was evaluated in this study. In total, 648 oneday-old Arbor Acres broiler chicks were randomly distributed into nine numerically-equal treatment groups: $T_{1}$ (control group; fed a basal diet) $\mathrm{T}_{2}$ (fed the basal diet supplemented with 1\% LJP); $\mathrm{T}_{3}$ (fed the basal diet supplemented with $300 \mathrm{mg}$ cecropin/ $/ \mathrm{kg}$ ); and $\mathrm{T}_{4}, \mathrm{~T}_{5}, \mathrm{~T}_{6}, \mathrm{~T}_{7}, \mathrm{~T}_{8}$ and $T_{9}$, individually fed with the dietary supplemented with varying levels of LJP and cecropin). Compared with the control, dietary of LJP or cecropin supplementation slightly improved feed conversion ratio (FCR). However, the dietary supplementation of LJP combined with cecropin significantly improved broiler growth performance during the periods of $1-21,21-42$, and $1-42$ days $(p<0.05)$. The dietary supplementation of $3 \%$ LJP combined with $300 \mathrm{mg} / \mathrm{kg}$ cecropin significantly increased FCR, and serum Newcastle disease antibody titers and lymphocyte numbers during the periods of $1-21,21-42$, and $1-42$ days $(p<0.05)$. Cecal microorganisms were cultivated and the number of Escherichia coli and Lactobacillus colonies were counted. The dietary supplementation of LJP combined with cecropin remarkably inhibited $E$. coli growth and increased Lactobacillus growth. The results of this study demonstrate the feasibility of using LJP and cecropin as feed supplement for improving the growth performance and enhancing the immune function of broilers.

\section{INTRODUCTION}

There has been growing interest to control the use of antibiotics in poultry feeds over recent years because the high daily intake of antibiotic growth promoters (AGP) is considered a possible risk factor for the increasing microbial resistance against antibiotics, and the presence of AGP residues in animal products may cause serious health problems to the consumers (Castañon, 2007). Therefore, the need for AGP alternatives in poultry production is increasing and the contribution of seaweed may be considerable (Patterson \& Burkholder, 2003). Laminaria japonica, a species of seaweed native to coastal waters, is extensively used in the food, animal feed, and pharmaceutical industries due to its abundant nutrient contents, including proteins, soluble dietary fibers, minerals, vitamins, phytochemicals, and polyunsaturated fatty acids (Mohamed et al., 2012; Abudabos et al., 2013; Kulshreshtha et al., 2014; Nitschke \& Stengel, 2015). Moreover, Laminaria japonica has potential medicinal effects, as shown by the enhancement of the resistance of finishing pigs to gastrointestinal tract pathogens, of humoral immune function in piglets, and regulation of the gastrointestinal function and growth of pigs (Wang et al., 2000; Leonard et al., 2010). Bai et al. (2013) reported that the dietary addition of Laminaria japonica powder (LJP) enhanced the growth performance and improved the immune function 
of chickens during the entire rearing period, and Wang et al. (2014) showed that LJP in broiler diets increased their metabolic and growth rates. However, annually, Laminaria japonica is mostly used as food and as raw material in pharmaceutical industry, and only a small volume is used in live stock production. Moreover, the growth period of Laminaria japonica is long.

Alternatively, antibacterial peptides not only can overcome these disadvantages mentioned above, but also have additional advantages, such as resistance to high temperature, safety, easy degradation and does not promote drug resistance. Antibacterial peptides have attracted great interest in the poultry industry over the past few decades (Izadpanah \& Gallo, 2005; Rajanbabu \& Chen, 2011; Li et al., 2011; Abraham et al., 2014; Park et al., 2015). Previous reports on antibacterial peptides as feed additives have presented contradictory results because of their complex production process and high production cost. In order to overcome these disadvantages, Wang et al. (2011) proposed that dietary supplementation of antibacterial peptides combined with other additive could be more effective in improving the growth performance and immune function of poultry. However, until now, co-supplementation of dietary LJP and cecropin for improving the growth performance and immune function of broilers was rarely reported.

Cecropin extracted from Bombyx mori (silkworm) can improve the growth performance and immune function of poultry (Park et al., 2015). Wen \& He (2012) reported that cecropin had a positive quadratic effect on weight gain and increased nutrient utilization for both grower and finisher broilers. Therefore, in the current study, the influence of co-supplementation of dietary LJP and cecropin on the growth performance and immune function of broilers was first examined.

\section{MATERIALS AND METHODS}

All experimental procedures were performed according to the National Institutes of Health Guidelines for Use of Laboratory Animals and approved by the Institutional Animal Care and Use Committee of Lüliang University, China (NIH Pub. No. 85-23, revised 1996).

\section{Materials}

Laminaria japonica powder (LJP) was purchased from Qingdao Hanfeng Biotechnology Corporation (Shandong, China). The cecropin extracted from Bombyx mori was purchased from Shanghai Livestock Biotechnology Corporation (Shanghai, China).

\section{Bird management}

A total of 648 one-day-old Arbor Acres broiler chicks (1 male:1 female) were purchased from Da Xiang company (Shanxi, China). Chicks were randomly distributed into nine treatment groups, with 6 replicates of 6 males and 6 females each (Table 1): $T_{1}$, fed the basal diet formulated to meet the nutritional requirement of chicks according to the NRC (1994) recommendations, Table 2$) ; T_{2}$, fed the basal diet and $1 \%$ LJP; $T_{3}$, fed the basal diet and 300mg cecropin/ $\mathrm{kg}$; and $\mathrm{T}_{4}, \mathrm{~T}_{5}, \mathrm{~T}_{6}, \mathrm{~T}_{7}, \mathrm{~T}_{8}$ and $\mathrm{T}_{9}$, each fed the basal diet supplemented with varying combinations of LJP and cecropin levels, as described in Table 1. The chicks were reared on the poultry farm of WenshuilinKe Biological Ecology company (Shanxi, China), under well-controlled conditions and according to standard management practices. Birds were fed adlibitum for 42 days.

Table 1 - The distribution of 168 chicks in ninetrial groups

\begin{tabular}{lcl}
\hline Treatments & Number of chickens & \multicolumn{1}{c}{ Composition } \\
\hline $\mathrm{T}_{1}$ & $12 \times 6$ & Control (basal diet) \\
$\mathrm{T}_{2}$ & $12 \times 6$ & Basal diet +1\% $\mathrm{LJP}$ \\
$\mathrm{T}_{3}$ & $12 \times 6$ & Basal diet +300 mg/kgcecropin \\
$\mathrm{T}_{4}$ & $12 \times 6$ & Basal diet+1\%LJP+300 mg/kgcecropin \\
$\mathrm{T}_{5}$ & $12 \times 6$ & Basal diet+3\%LP+300 mg/kgcecropin \\
$\mathrm{T}_{6}$ & $12 \times 6$ & Basal diet+5\%LJP+300 mg/kgcecropin \\
$\mathrm{T}_{7}$ & $12 \times 6$ & Basal diet+1\%LJP+600 mg/kgcecropin \\
$\mathrm{T}_{8}$ & $12 \times 6$ & Basal diet+3\%LJP+600 mg/kgcecropin \\
$\mathrm{T}_{9}$ & $12 \times 6$ & Basal diet+5\%LJP+600 mg/kgcecropin \\
\hline
\end{tabular}

\section{Growth performance}

Growth performance was evaluated as described by Bai et al. (2013). The total body weight of each group was measured on d 1,21, and 42, respectively, and expressed in g. Average daily gain (ADG) was calculated using the following equation:

$$
A D G=\frac{M_{2}-M_{1}}{7_{2 n}}
$$

$M_{1}$ : total body weight of each measured on $\mathrm{d} 0$;

$M_{2}$ : total body weight of each group measured on d 21 and 42;

$\mathrm{n}$ : number of days of the rearing period (21 and 42 days)

The total feed intake of each group was individually determined by measuring feed residue on $\mathrm{d} 21$ and 42 , and expressed in $\mathrm{g}$. Average daily feed intake (ADFI) was calculated using the following equation:

$$
A D G=\frac{m_{2}-m_{1}}{7_{2 n}}
$$


Table 2 - Composition of the basal diet.

\begin{tabular}{|c|c|c|c|c|c|}
\hline \multirow[t]{2}{*}{ Ingredients } & \multicolumn{2}{|c|}{ Content (\%) } & \multicolumn{3}{|c|}{ Nutrient levels ${ }^{2}$} \\
\hline & $1-21 d$ & $22-42 d$ & & $1-21 d$ & $22 \sim 42 d$ \\
\hline Corn & 57.90 & 62.51 & $\mathrm{ME}(\mathrm{MJ} / \mathrm{kg})$ & 12.55 & 12.85 \\
\hline Rapeseed meal & 3.00 & 4.00 & $\mathrm{CP}(\%)$ & 21.49 & 21.38 \\
\hline Cotton seed meal & 3.00 & 4.00 & $\mathrm{Ca}(\%)$ & 1.00 & 0.80 \\
\hline Soybean meal & 30.00 & 23.00 & Met (\%) & 0.52 & 0.40 \\
\hline Soybean oil & 1.50 & 2.20 & Lys (\%) & 1.20 & 1.00 \\
\hline $\mathrm{Ca}\left(\mathrm{HCO}_{3}\right)_{2}$ & 1.60 & 1.50 & & & \\
\hline Limestone & 1.37 & 1.30 & & & \\
\hline Salt & 0.30 & 0.30 & & & \\
\hline Premix ${ }^{1}$ & 1.00 & 1.00 & & & \\
\hline Met & 0.19 & 0.10 & & & \\
\hline Lys & 0.14 & 0.09 & & & \\
\hline Total & 100.00 & 100.00 & & & \\
\hline
\end{tabular}

'Provided per kilogram of diet: $8 \mathrm{mg}$ copper,60 mg iron,40 mg zinc,50 mg manganese, $0.2 \mathrm{mg}$ selenium, $0.2 \mathrm{mg}$ iodine, $10000 \mathrm{IU}$ vitamin A,2 $750 \mathrm{IU}$ vitamin D,20 IU vitamin E,2 mg vitamin $\mathrm{K}, 1.5 \mathrm{mg}$ thiamin, $6 \mathrm{mg}$ riboflavin, $3.54 \mathrm{mg}$ calcium, $0.42 \mathrm{mg}$ phosphorus, $20 \mathrm{mg}$ niacin, $2 \mathrm{mg}$ pyridoxine, $0.5 \mathrm{mg}$; folacin, $0.2 \mathrm{mgbiotin}, 200 \mathrm{mg}$ choline chloride.

${ }^{2}$ Nutrient levels were the calculated values. Abbreviation: ME: metabolic energy; CP: crude protein; Ca: Calcium; Met: methionine; Lys: Lysine.

$m_{1}$ : feed offer weight of each group on d 0;

$m_{2}$ : feed residue weight of each group in the feeder on $\mathrm{d} 21$ and 42 ;

$\mathrm{n}$ : number of days of the rearing period (21 and 42 days)

Feed conversion ratio (FCR) was calculated using the following equation:

$$
\mathrm{FCR}=\frac{X}{Y}
$$

$X$ : total feed intake (FI);

$Y$ : total body weight gain (BWG).

\section{Newcastle disease immunization}

Inactivated New castle disease virus (INDV) vaccine and Newcastle disease virus IV strain vaccine (NDV-IV) were purchased from Heilongjiang biological product Co., Ltd, Haerbin, P.R. China. Birds were immunized according to the procedure of Huang et al. (2014): 7-d-old birds were firstly vaccinated against NDV via intramuscular injection and against IV via eyedrop.

\section{Serum collection and processing}

On d 21 and 42, two birds per replicate were randomly selected for blood collection from their wing veins. The sera were centrifuged and frozen at $-20^{\circ} \mathrm{C}$. The serum was prepared according to the procedure of Virden et al.(2004)

\section{Newcastle disease antibody titering}

Newcastle disease (ND) antibody titers were determined by hemagglutination and hemagglutination inhibition assays (Wang et al., 2014). The abovementioned serum samples were 2-fold serially diluted in a 96-well V-shaped bottom microtiter plate with 50 $\mu \mathrm{L}$ phosphate buffered solution $(\mathrm{pH} 7.4)$ in each well. Then, $50 \mu \mathrm{L}$ of NDV antigen (4 HA units) was added into each well, except for the last row, which served as the control. Serum dilutions ranged from $1: 2$ to $1: 2048$. The plate was incubated at $37^{\circ} \mathrm{C}$ for $10 \mathrm{~min}$, after which $50 \mu \mathrm{L}$ of $1 \%$ rooster erythrocyte suspension was added to each well, and plates were re-incubated for $30 \mathrm{~min}$. Positive and negative serum samples, erythrocytes, and antigens were also included as controls. The highest dilution of the serum that caused complete inhibition was considered the endpoint. Mean titer was expressed as reciprocal $\log 2$ values of the highest dilution that displayed hemagglutination inhibition assays.

\section{Nonspecific acid esteraselymphocyte assay}

Nonspecific acid esteraselymphocyte percentage was determined by the acid a-naphthalene acetic acid esterase staining method (Ma et al., 2015). At 21 and 42 day of age, the blood of two randomly selected birds per replicate was collected from the wing veins. One drop blood was uniformly smeared on a glass slide, which was dried by cool wind. The slide was immersed in a methanal-acetone solution (1:50) for 1 minat $4^{\circ} \mathrm{C}$, washed with double-distilled water for 3 min, and dried by cool wind at room temperature. Slides were then incubated in the incubation solution for $1.5 \mathrm{~h}$ at $37^{\circ} \mathrm{C}$, washed with double-distilled water for $3 \mathrm{~min}$, immersed in methyl green stain for $1 \mathrm{~min}$, washed with double-distilled water for 3 min, dried at room temperature and the number of cells was counted under a microscope. Nonspecific acid esterase lymphocyte percentage (NAELP) was calculated using the following equation: 


$$
\text { NAELP }=\frac{N_{1}}{N_{0}} \times 100 \%
$$

$\mathrm{N}_{1}$ : number of acid-esterase positive cells;

$\mathrm{N}_{0}$ : total number of lymphocytes.

\section{Serum lysozyme activity assay}

Serum lysozyme activity was measured using an ELISA kit purchased from Nanjing Institute of Biological Engineering. Serum samples were diluted 1:500 and incubated in 96-well microtiter plates, and the assay was performed according to the manufacturer's recommendations.

\section{Escherichia coli and Lactobacillus spp counts and immune organ index}

The number of $E$. coli and Lactobacillus colonies as counted according to the method of Liu et al. (2013).

A volume of $0.5 \mathrm{~g}$ of cecal contents were recursively diluted in $4.5 \mathrm{~mL}$ sterile water under sterile conditions, and placed into a sterile incubator at $37^{\circ} \mathrm{C}$. E. coli was cultured in Makanke media for $24 \mathrm{~h}$ and Lactobacillus was in MRS media for $48 \mathrm{~h}$, respectively. After incubation, colonies were counted, and bacterial number was expressed as an algorithm relative to the entire bacterial community in $1 \mathrm{~g}$ intestinal contents $[\lg (\mathrm{CFU} / \mathrm{g})]$.

On d 42, all birds were killed by cervical dislocation, and the spleen, bursa of Fabricius and thymus were collected and weighed to calculate immune organ index $(\mathrm{g} / \mathrm{kg})$ as the fresh weigh of the immune organ relative to live weight.

\section{Statistical analysis}

The data were statistical analyzed using SAS 9.0. Treatments were compared using two-way analysis of variance (ANOVA), followed by Duncan's multiple comparison tests. For all statistical analysis, $p<0.05$ was considered to be significant.

\section{RESULTS}

Effect of the dietary co-supplementation of LJP and cecropin on broiler growth performance

In order to understand the effects of the dietary co-supplementation of LJP and cecropin on the growth performance, broiler BWG, ADG, ADFI and FCR were measured and the results are shown in Table 3.

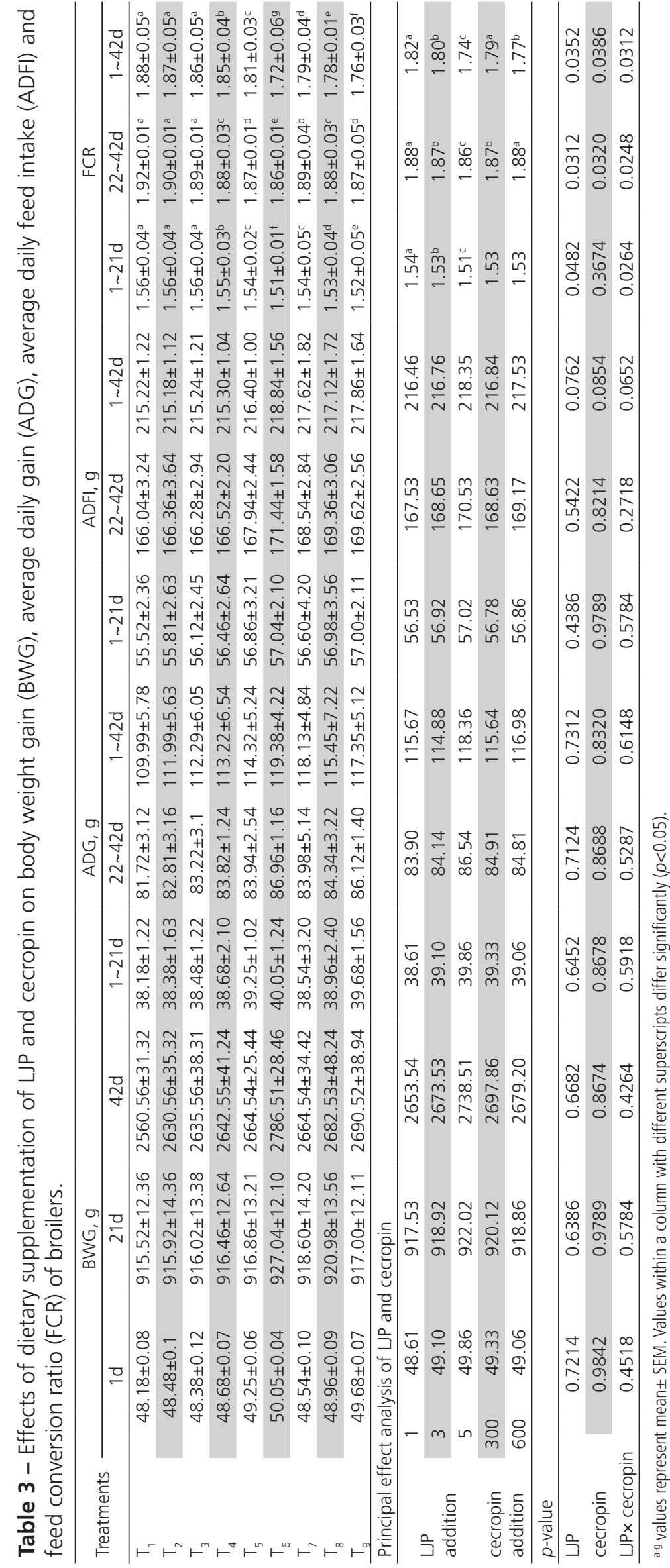


Compared with the control, the BWG, ADG and ADFI of $T_{2}$ (basal diet $+1 \%$ LJP), $T_{3}$ (basal diet +300 $\mathrm{mg} / \mathrm{kg}$ cecropin), $\mathrm{T}_{4}$ (basal diet $+1 \%$ LJP and $300 \mathrm{~g} / \mathrm{kg}$ cecropin), $T_{5}$ (basal diet + $3 \%$ LJP and $300 \mathrm{~g} / \mathrm{kg}$ cecropin), $\mathrm{T}_{6}$ (basal diet $+5 \%$ LJP and $300 \mathrm{~g} / \mathrm{kg}$ cecropin), $\mathrm{T}_{7}$ (basal diet $+1 \%$ LJP and $600 \mathrm{~g} / \mathrm{kg}$ cecropin), $\mathrm{T}_{8}$ (basal diet $+3 \%$ LJP and $600 \mathrm{~g} / \mathrm{kg}$ cecropin), $\mathrm{T}_{9}$ (basal diet $+5 \%$ LJP and $600 \mathrm{~g} / \mathrm{kg}$ cecropin) birds was no significantly different on $d 21$ and 42 ( $p>0.05$ ). The FCR of the experimental groups fed different LJP levels combined with cecropin were not statistically different on d 21 ( $p>0.05)$, but were statistically difference on d $42(p<0.05)$. The LJP and cecropin interaction did not significantly affect BWG, ADG, or ADFI on d 1, 21, and 42 , but FCR significantly decreased from 1.82 to 1.77 at each stage $(p<0.05)$.

No BWG, ADWG, or ADFI differences ( $p>0.05$ ) were detected among treatments on d 21 or 42 . However, considering the entire rearing period ( $d$ 1-42), the dietary supplementation of LJP and cecropin tended $(p<0.10)$ to increase ADFI compared with the control treatment. Relative to FCR results, no differences were detected ( $p>0.05$ ) among $\mathrm{T}_{1}$ (basal diet), $\mathrm{T}_{2}$ (basal diet $+1 \%$ LJP), $\mathrm{T}_{3}$ (basal diet $+300 \mathrm{mg} / \mathrm{kg}$ cecropin) groups during none of the evaluated periods. However, during the period of $1-21 d$, significantly lower FCR $(p<0.05)$ was obtained with $T_{6}$, followed by $T_{9}$ (basal diet $+5 \%$ LJP and $600 \mathrm{mg}$ cecropin/kg), $\mathrm{T}_{8}$ (basal diet + 3\% LJP and $600 \mathrm{mg}$ cecropin $/ \mathrm{kg}$ ), $\mathrm{T}_{4}$ (basal diet $+1 \%$ LJP and $300 \mathrm{mg}$ cecropin/kg).

\section{Effects of dietary LJP and cecropin on serum ND antibody titers and immune organ index}

The effect of dietary LJP and cecropin addition on the immune organ index of broilers was evaluated by serum NDV antibody titers and the results are shown in Table 4.

The dietary supplementation of LJP did not significantly influence $\mathrm{HI}$ or ANAE values determined on $d 21$ and $d 42(p>0.05)$. However, the dietary supplementation of cecropin significant increased both $\mathrm{HI}$ and ANAE values on $\mathrm{d} 21$ and $\mathrm{d} 42(p<0.05)$. Moreover, the dietary supplementation of $1 \%$ LJP plus300 mg/kg cecropin, 3\% LJP plus $300 \mathrm{mg} / \mathrm{kg}$ cecropin, 5\% LJP plus $300 \mathrm{mg} / \mathrm{kg}$ cecropin, $1 \%$ LJP plus 600 mg/kg cecropin , 3\% LJP plus 600 mg/kg cecropin and $5 \%$ LJP plus $300 \mathrm{mg} / \mathrm{kg}$ cecropin significantly increased Newcastle disease antibody titers and ANAE lymphocyte number on $d 21$ and $42(p<0.05)$.

Table 4 - Effects of dietary LJP and cecropin on serum Newcastle disease antibody titers.

\begin{tabular}{|c|c|c|c|c|c|}
\hline \multirow{2}{*}{ Treatments } & & \multicolumn{2}{|c|}{$21 d$} & \multicolumn{2}{|c|}{$42 d$} \\
\hline & & $\mathrm{HI} \log _{2} \mathrm{~N}$ & $\mathrm{ANAE}^{+} \%$ & $\mathrm{HI} \log _{2} \mathrm{~N}$ & $\mathrm{ANAE}^{+} \%$ \\
\hline$T_{1}$ & & $1.75 \pm 0.50^{d}$ & $29.25 \pm 2.02^{d}$ & $5.00 \pm 1.00^{d}$ & $32.25 \pm 2.65^{d}$ \\
\hline $\mathrm{T}_{2}$ & & $1.85 \pm 0.50^{\mathrm{cd}}$ & $30.45 \pm 2.12^{\text {cd }}$ & $5.12 \pm 0.50^{\mathrm{cd}}$ & $33.65 \pm 2.36^{\mathrm{cd}}$ \\
\hline $\mathrm{T}_{3}$ & & $2.12 \pm 0.50^{\mathrm{cd}}$ & $31.10 \pm 2.32^{\mathrm{cd}}$ & $5.18 \pm 0.50^{\mathrm{cd}}$ & $34.10 \pm 2.42^{\mathrm{cd}}$ \\
\hline $\mathrm{T}_{4}$ & & $2.25 \pm 0.50^{c d}$ & $31.50 \pm 2.52^{\mathrm{cd}}$ & $5.25 \pm 0.50^{c d}$ & $34.50 \pm 2.52^{\mathrm{cd}}$ \\
\hline $\mathrm{T}_{5}$ & & $2.50 \pm 1.00^{c}$ & $33.75 \pm 2.08^{c}$ & $5.50 \pm 0.50^{c}$ & $36.50 \pm 2.53^{c}$ \\
\hline $\mathrm{T}_{6}$ & & $3.00 \pm 0.40^{a}$ & $40.50 \pm 1.26^{a}$ & $6.50 \pm 0.50^{a}$ & $44.75 \pm 2.42^{a}$ \\
\hline $\mathrm{T}_{7}$ & & $2.50 \pm 0.50^{c}$ & $35.25 \pm 2.50^{\mathrm{bc}}$ & $5.50 \pm 1.00^{c}$ & $37.50 \pm 2.40^{b c}$ \\
\hline $\mathrm{T}_{8}$ & & $2.75 \pm 0.45^{b}$ & $37.25 \pm 2.06^{b}$ & $6.00 \pm 1.15^{b}$ & $39.50 \pm 2.60^{b}$ \\
\hline$T_{9}$ & & $2.90 \pm 1.00^{\mathrm{ab}}$ & $39.25 \pm 2.52^{\mathrm{ab}}$ & $6.25 \pm 1.00^{\mathrm{ab}}$ & $42.50 \pm 2.50^{\mathrm{ab}}$ \\
\hline \multicolumn{6}{|c|}{ Principal effect analysis of LJP and cecropin } \\
\hline \multirow{3}{*}{$\begin{array}{l}\text { LJP } \\
\text { addition }\end{array}$} & 1 & $2.37^{c}$ & $33.37^{c}$ & $5.37^{c}$ & $36.00^{c}$ \\
\hline & 3 & $2.62^{b}$ & $35.50^{b}$ & $5.75^{b}$ & $38.00^{b}$ \\
\hline & 5 & $2.95^{\mathrm{a}}$ & $39.87^{a}$ & $6.37^{a}$ & $43.62^{a}$ \\
\hline cecropin & 300 & $2.58^{b}$ & $35.25^{b}$ & $5.75^{b}$ & $38.58^{b}$ \\
\hline addition & 600 & $2.72^{a}$ & $37.25^{\mathrm{a}}$ & $5.92^{\mathrm{a}}$ & $39.83^{a}$ \\
\hline \multicolumn{6}{|l|}{$p$-value } \\
\hline LJP & & 0.0012 & 0.0076 & 0.0052 & 0.0062 \\
\hline cecropin & & 0.0002 & 0.0001 & 0.0010 & 0.0001 \\
\hline LPP cecropin & & 0.0004 & 0.0001 & 0.0002 & 0.0001 \\
\hline
\end{tabular}

a-d values represent mean \pm SEM. Values within a column with different superscripts differ significantly $(p<0.05)$.

The results of the effect of LJP and cecropin dietary supplementation on immune organ (bursa, spleen, and thymus) indexes are shown in Table 5. Broilers fed diets supplemented with LJP $(1 \%, 3 \%$ and $5 \%)$, cecropin
(300 mg/kg and600 mg/kg ) or 1\% LJP plus $300 \mathrm{mg} /$ $\mathrm{kg}$ cecropin, 3\% LJP plus $300 \mathrm{mg} / \mathrm{kg}$ cecropin, $5 \%$ LJP plus $300 \mathrm{mg} / \mathrm{kg}$ cecropin, 1\% LJP plus $600 \mathrm{mg} / \mathrm{kg}$ cecropin, 3\% LJP plus $600 \mathrm{mg} / \mathrm{kg}$ cecropin and 5\% LJP 
Table 5 - Effect of dietary supplementation of LJP and cecropin on the immune function of broilers $(\mathrm{g} / \mathrm{kg})$.

\begin{tabular}{|c|c|c|c|c|c|c|c|}
\hline \multirow{2}{*}{ Treatments } & \multicolumn{4}{|c|}{$21 d$} & \multicolumn{3}{|c|}{$42 d$} \\
\hline & & Bursal index & Spleen index & Thymus index & Bursal index & Spleen index & Thymus index \\
\hline$T_{1}$ & & $2.48 \pm 0.06$ & $0.93 \pm 0.17 c$ & $4.48 \pm 0.14^{c}$ & $1.56 \pm 0.09^{e}$ & $1.25 \pm 0.17$ & $5.05 \pm 0.14$ \\
\hline $\mathrm{T}_{2}$ & & $2.49 \pm 0.04$ & $0.94 \pm 0.15^{c}$ & $4.79 \pm 0.14^{c}$ & $1.58 \pm 0.09^{e}$ & $1.26 \pm 0.14$ & $5.08 \pm 0.14$ \\
\hline $\mathrm{T}_{3}$ & & $2.50 \pm 0.03$ & $0.95 \pm 0.14 c$ & $4.82 \pm 0.13^{c}$ & $1.61 \pm 0.08^{e}$ & $1.27 \pm 0.13$ & $5.10 \pm 0.13$ \\
\hline $\mathrm{T}_{4}$ & & $2.52 \pm 0.02$ & $0.96 \pm 0.12^{b c}$ & $5.12 \pm 0.13^{b c}$ & $1.64 \pm 0.08^{d}$ & $1.28 \pm 0.12$ & $5.12 \pm 0.13$ \\
\hline $\mathrm{T}_{5}$ & & $2.58 \pm 0.02$ & $0.99 \pm 0.15^{b c}$ & $5.14 \pm 0.12^{b c}$ & $1.78 \pm 0.05^{c}$ & $1.30 \pm 0.15$ & $5.24 \pm 0.12$ \\
\hline $\mathrm{T}_{6}$ & & $2.76 \pm 0.04$ & $1.06 \pm 0.11^{\mathrm{a}}$ & $6.45 \pm 0.11^{\mathrm{a}}$ & $2.16 \pm 0.04^{a}$ & $1.38 \pm 0.11$ & $5.64 \pm 0.11$ \\
\hline $\mathrm{T}_{7}$ & & $2.65 \pm 0.06$ & $1.02 \pm 0.13^{b}$ & $5.21 \pm 0.15^{b}$ & $1.81 \pm 0.06^{b c}$ & $1.32 \pm 0.13$ & $5.46 \pm 0.15$ \\
\hline $\mathrm{T}_{8}$ & & $2.68 \pm 0.03$ & $1.03 \pm 0.12^{\mathrm{ab}}$ & $6.05 \pm 0.14^{\mathrm{ab}}$ & $1.88 \pm 0.03^{b c}$ & $1.35 \pm 0.12$ & $5.53 \pm 0.14$ \\
\hline $\mathrm{T}_{9}$ & & $2.72 \pm 0.06$ & $1.04 \pm 0.11^{\mathrm{ab}}$ & $6.09 \pm 0.15^{\mathrm{ab}}$ & $1.95 \pm 0.06^{b}$ & $1.36 \pm 0.11$ & $5.56 \pm 0.15$ \\
\hline \multicolumn{8}{|c|}{ Principal effect analysis of LJP and cecropin } \\
\hline \multirow{3}{*}{ LJP addition } & 1 & 2.58 & $0.99^{c}$ & $5.16^{c}$ & $1.73^{c}$ & 1.30 & 5.29 \\
\hline & 3 & 2.63 & $1.01^{\mathrm{b}}$ & $5.60^{b}$ & $1.83^{b}$ & 1.33 & 5.38 \\
\hline & 5 & 2.74 & $1.05^{\mathrm{a}}$ & $6.27^{\mathrm{a}}$ & $2.06^{a}$ & 1.37 & 5.60 \\
\hline \multirow{2}{*}{$\begin{array}{l}\text { Ceropin } \\
\text { addition }\end{array}$} & 300 & 2.62 & $1.00^{\mathrm{b}}$ & $5.57^{b}$ & $1.86^{\mathrm{b}}$ & 1.32 & 5.33 \\
\hline & 600 & 2.68 & $1.03^{\mathrm{a}}$ & $5.78^{\mathrm{a}}$ & $1.88^{\mathrm{a}}$ & 1.34 & 5.52 \\
\hline \multicolumn{8}{|l|}{$p$-value } \\
\hline \multirow{3}{*}{$\begin{array}{l}\text { LJP } \\
\text { ceropin } \\
\text { LPxceronin }\end{array}$} & & 0.9382 & 0.0376 & 0.0282 & 0.0211 & 0.0942 & 0.0914 \\
\hline & & 0.9312 & 0.0382 & 0.0412 & 0.0358 & 0.0928 & 0.0956 \\
\hline & & 0.8204 & 0.0284 & 0.0264 & 0.0201 & 0.0876 & 0.0902 \\
\hline
\end{tabular}

a-e values represent mean \pm SEM. Values within a column with different superscripts differ significantly $(p<0.05)$.

plus $300 \mathrm{mg} / \mathrm{kg}$ cecropin significantly increased spleen and thymus indexes on $\mathrm{d} 21$ and bursa of Fabricius index on d $42(p<0.05)$, but did not affect broilers' bursa of Fabricius index on $\mathrm{d} 21$ and spleen index and thymus index on $d 42$ ( $p>0.05)$. The interaction of LJP and cecropin significantly increased broilers' spleen index and thymus index in broilers on days 21 and $42(p<0.05)$.
Effects of dietary LJP and cecropin on $E$. coli and Lactobacillus spp counts

E. coli and Lactobacillus results are shown in Table 6. The dietary supplementation of LJP did not significantly inhibit E. coli growth $(p>0.05)$ and promoted Lactobacillus growth in the ceca of broilers on $\mathrm{d} 21$ and $42(p<0.05)$. The dietary supplementation of cecropin

Table 6 - Effect of dietary supplementation of LJP and cecropin on E. coli and Lactobacillus (lg CFU/g) in the cecum of broilers.

\begin{tabular}{|c|c|c|c|c|c|}
\hline \multirow{2}{*}{ Treatments } & & \multicolumn{2}{|c|}{$21 d$} & \multicolumn{2}{|c|}{$42 d$} \\
\hline & & E. coli & Lactobacillus & E. coli & Lactobacillus \\
\hline $\mathrm{T}_{1}$ & & $7.24 \pm 0.05^{a}$ & $7.85 \pm 0.04^{c}$ & $8.14 \pm 0.02^{a}$ & $8.50 \pm 0.03^{d}$ \\
\hline $\mathrm{T}_{2}$ & & $7.04 \pm 0.04^{a}$ & $8.05 \pm 0.04^{c}$ & $8.04 \pm 0.04^{a}$ & $8.53 \pm 0.05^{d}$ \\
\hline $\mathrm{T}_{3}$ & & $6.85 \pm 0.03^{a}$ & $8.10 \pm 0.04^{c}$ & $7.74 \pm 0.05^{a}$ & $8.55 \pm 0.05^{d}$ \\
\hline $\mathrm{T}_{4}$ & & $6.70 \pm 0.02^{a b}$ & $8.13 \pm 0.08^{b c}$ & $7.51 \pm 0.06^{b}$ & $8.54 \pm 0.08^{c d}$ \\
\hline $\mathrm{T}_{5}$ & & $6.54 \pm 0.02^{b c}$ & $8.17 \pm 0.03^{b c}$ & $7.32 \pm 0.04^{b c}$ & $8.76 \pm 0.05^{b c}$ \\
\hline $\mathrm{T}_{6}$ & & $6.26 \pm 0.08^{d}$ & $8.34 \pm 0.02^{a}$ & $7.05 \pm 0.04^{d}$ & $9.12 \pm 0.06^{a}$ \\
\hline $\mathrm{T}_{7}$ & & $6.64 \pm 0.06^{b}$ & $8.19 \pm 0.03^{b}$ & $7.35 \pm 0.06^{b c}$ & $8.62 \pm 0.02^{c}$ \\
\hline $\mathrm{T}_{8}$ & & $6.42 \pm 0.04^{b c}$ & $8.25 \pm 0.02^{a b}$ & $7.20 \pm 0.02^{c}$ & $8.83 \pm 0.02^{b}$ \\
\hline $\mathrm{T}_{9}$ & & $6.30 \pm 0.02^{c}$ & $8.28 \pm 0.04^{\mathrm{ab}}$ & $7.08 \pm 0.06^{c d}$ & $8.94 \pm 0.06^{a b}$ \\
\hline \multicolumn{6}{|c|}{ Principal effect analysis of LJP and ceropin } \\
\hline \multirow{3}{*}{ LJP addition } & 1 & $6.67^{a}$ & $8.16^{c}$ & $7.43^{a}$ & $8.58^{c}$ \\
\hline & 3 & $6.48^{b}$ & $8.21^{b}$ & $7.26^{b}$ & $8.79^{b}$ \\
\hline & 5 & $6.28^{c}$ & $8.31^{a}$ & $7.06^{c}$ & $9.03^{a}$ \\
\hline \multirow{2}{*}{ Cecropin addition } & 300 & $6.50^{a}$ & $8.21^{b}$ & $7.29^{a}$ & $8.81^{b}$ \\
\hline & 600 & $6.45^{b}$ & $8.24^{a}$ & $7.21^{b}$ & $8.88^{a}$ \\
\hline \multicolumn{6}{|l|}{$p$-value } \\
\hline LJP & & 0.0222 & 0.0276 & 0.0271 & 0.0292 \\
\hline cecropin & & 0.0302 & 0.0242 & 0.0413 & 0.0426 \\
\hline LJP×ceropin & & 0.0204 & 0.0184 & 0.0251 & 0.0218 \\
\hline
\end{tabular}

${ }^{a-d}$ Values represent the mean. Values within a column with different superscripts differ significantly $(p<0.05)$. 
significantly inhibited $E$. coli growth on d 21 and 42 $(p<0.05)$, but not significantly influence Lactobacillus growth $(p>0.05)$. The dietary supplementation of $5 \%$ LJP combined with300 mg cecropin/ $\mathrm{kg}$ and 5\% LJP combined with $600 \mathrm{mg}$ cecropin/kg significantly reduced $E$. coli counts and increased Lactobacillus counts on $d 21$ and $42 \quad(p<0.05)$. The dietary supplementation of LJP (1-3\%) combined with 300 $\mathrm{mg}$ cecropin/kg or $600 \mathrm{mg}$ cecropin/kg significantly reduced E. coli counts on $d 21$ and $42 \quad(p<0.05)$. However, the dietary supplementation of LJP (1-3\%) did not significantly increased Lactobacillus counts ( $p>0.05)$.

\section{DISCUSSION}

\section{Growth performance assays}

The dietary supplementation of LJP significantly improved broiler FCR during all evaluated periods, and increased ADFI from 22 to 42 days and from 1 to 42 days. These results suggest that the dietary supplementation of LJP may have increased dietary energy content during the stage of rapidly increasing body weight (from day 22 to day 42), as previously demonstrated by Wong \& Cheung (2001). Literature studies report that Laminaria japonica is rich in proteins, soluble dietary fibers, minerals, vitamins, phytochemicals and polyunsaturated fatty acids (Abudabos et al., 2013; Kulshreshtha et al., 2014; Mohamed et al., 2012; Nitschke \& Stengel, 2015). Moreover, the dietary supplementation of cecropin significantly improved broiler FCR from 22 to 42 days and from 1 to 42 days of age in the present experiment. Cecropin accelerates nutrient metabolism and improves nutrient utilization rate in broilers (Ganz, 2003). Wen \& He (2012) reported that cecropin had a positive quadratic effect on weight gain and increased nutrient utilization in both grower and finisher broilers. Cecropin also reduces diarrhea incidence in chickens and enhances the absorption of ingested nutrients (Li et al., 2008). Wang et al. (2007) reported that cecropin was more efficient than antibiotics for the prevention and control diarrhea of weaned piglets. Wu et al. (2012) reported that cecropin improved pig performance by enhancing their immune status and nitrogen and energy retention, as well as reducing intestinal pathogens in weaned piglets. Based on these results, it can be concluded that the dietary supplementation of LJP and cecropin may reduce diarrhea and enhance the absorption of ingested nutrients of broilers during the feeding stage.
The co-supplementation of LJP with cecropin significantly decreased broiler FCR during the periods of $1-21,21-42$, and $1-42$ days of age $(p<0.05)$. This result indicates that the supplementation of LJP and cecropin was able to accelerate nutrient absorption and utilization, and to enhance the live performance during the entire production cycle (Bouchet et al., 2014), and demonstrate the synergistic effect of LJP and cecropin.

\section{Immune organ growth, ND titers and lymphocytes of broiler}

The dietary supplementation of cecropin significantly increased the indexes of the spleen and thymus in 21-d-old broilers and of the bursa of Fabricius index in 42-d-old broilers, which consistent with the results of Michailidis et al. (2012). These results were also observed with the co-supplementation of LJP and cecropin. In 21- and 42-d-old broilers, the dietary supplementation of LJP or cecropin, and their co-supplementation increased spleen, thymus, and bursa indexes, indicating the synergistic effect of LJP and cecropin on immune organ indexes. It might be caused by the stimulation of cecropin leading to the development of the thymus, spleen and bursa of fabricius.

The dietary supplementation of LJP, cecropin and LJP combined with cecropin significantly increase ND titers and lymphocyte numbers on days 21 and 42 . According to literature, the active substance of LJP, stimulates lymphocytes, changing their cell structure, which affects immunity (Immanuel et al., 2012).In addition, because cecropin causes membrane permeabilization of both gram-positive and gram-negative bacteria, it kills the bacteria in the intestinal tract, improving the immune function (Hui et al., 2002). These results demonstrated that cecropin and LJP act in synergy to enhance the immune function of broilers during the rearing period.

\section{The effect of LJP and cecropin on $E$. coli and Lactobacillus growth}

The normal flora distribution in the intestines ensures the healthy growth of broilers (Crhanova et al., 2011). The dietary supplementation of LJP, cecropin, or cecropin combined with LJP reduced the number of $E$. coli colonies, and increased the number of lacticacid bacterial colonies in the ceca during the feeding period, which may be explained by the synergic antiseptic effect of LJP and cecropin in inhibiting $E$. coli growth. Laminaria japonica as the potential medicine 
may enhance the resistance against gastrointestinal tract pathogens in fattening pigs, improve the humoral immune function of piglets, regulate gastrointestinal function and promote the growth of pigs (Wang et al., 2000; Leonard et al., 2010). It shown that cecropin causes membrane permeabilization of both grampositive and gram-negative bacteria, killing these bacteria in intestinal tract (Hui et al., 2002).On the other hand, the nutritional components of LJP may accelerate the replication of Lactobacillus, and optimize the intestinal microecological environment (Siahaan et al., 2014; Radulovich et al., 2015). In the present study, cecropin effectively inhibited the growth of competitive bacteria and increased lactic-acid bacteria number in the ceca of broilers. Previous literature studies reported that cecal microorganisms may be affected by the supplementation of either LJP or/and cecropin (Abdelsalam et al., 2010; Radulovich et al., 2015). It can be concluded that dietary supplementation of LJP combined with cecropin regulated the balance of the intestinal microbiota.

\section{CONCLUSION}

This study demonstrated that the co-supplementation of $5 \%$ LJP combined with $300 \mathrm{mg} / \mathrm{kg}$ cecropin LJP and cecropin in conventional diets improved the growth performance and enhanced the immune function of broilers. The study indicated that the dietary supplementation of LJP combined with cecropin is a technically viable strategy for broiler production.

\section{ACKNOWLEDGEMENTS}

The work was funded by the Lüliang university fund project (No. ZRXN201416). Many thanks are due to the poultry farm in WenshuiJinKe Biological Ecology Co., Ltd. (Shanxi, China)for the daily management of broiler chickens.

\section{REFERENCES}

Abdelsalam M, Isobe N, Yoshimura Y. Changes in the localization of immunoreactive avian beta-defensin-8, -10 and -12 in hen ovarian follicles during follicular growth. Poultry Science 2010;47(1):77-84.

Abraham P, George S, Kumar KS. Novel antibacterial peptides from the skin secretion of the indianbicoloured frog clinotarsuscurtipes. Biochimie 2014;97(1):144-151

Abudabos A, Okab A, Aljumaah R, Samara E, Abdoun K, Alhaidary A. Nutritional value of green seaweed (Ulva lactuca) for broiler chickens. Italian Journal of Animal Science 2013;12(2):612-620.
Bai S, Wu A, Ding X, Lei Y, Bai J, Zhang K, Chio J. Effects of probioticsupplemented diets on growth performance and intestinal immune characteristics of broiler chickens. Poultry Science 2013;92(3):663-670.

Bouchet AM, lannucci NB, Pastrian MB, Cascone O, Santos NC, Disalvo EA, et al. Biological activity of antibacterial peptides matches synergism between electrostatic and non-electrostatic forces. Colloids Surf B Biointerfaces 2014;114:363-371.

Castanon J. History of the use of antibiotic as growth promoters in European poultry feeds. Poultry Science 2007;86(11):2466-2471.

Crhanova M, Hradecka H, Faldynova M, Matulova M, Havlickova H, Sisak $\mathrm{F}$, et all. Immune response of chicken gut to natural colonization by gut microflora and to salmonella enterica serovar enteritidis infection. Infection \& Immunity 2011;79(7):2755.

Ganz T. Defensins: antimicrobial peptides of innate immunity. Nature Reviews Immunology 2003;3(9):710-720.

Huang Q, Li K, Zhang Z. immunization effect of four species of Chinese medicine on the newcastle disease. Chinese Journal of Traditional Veterinary Science 2014;1:6-8.

Hui L, Leung K, Chen HM. The combined effects of antibacterial peptide cecropin $\mathrm{a}$ and anti-cancer agents on leukemia cells. Anticancer Research 2002;22(5):2811.

Immanuel G, Sivagnanavelmurugan M, Marudhupandi T, Radhakrishnan S, Palavesam A. The effect of fucoidan from brown seaweed sargassum wightii on WSSV resistance and immune activity in shrimp penaeus monodon (fab). Fish Shellfish Immunol 2012;32(4):551-564.

Izadpanah A, Gallo RL. Antimicrobial peptides. Journal of the American Academy of Dermatology 2005;52(3):381-390.

Kulshreshtha G, Rathgeber B, Stratton G, Thomas N, Evans F, Critchley A, et al. Feed supplementation with red seaweeds, Chondruscrispus and Sarcodiothecagaudichaudii, affects performance, egg quality, and gut microbiota of layer hens. Poultry Science 2014;93(12):2991-3001.

Leonard S, Sweeney T, Bahar B, Lynch B, O'Doherty J. Effect of maternal fish oil and seaweed extract supplementation on colostrum and milk composition, humoral immune response, and performance of suckled piglets. Journal of Animal Science 2010;88(9):2988.

Li D, Geng Z, Zhu H, Wang C, Miao D, Chen P. Immunomodulatory activities of a new pentapeptide (bursopentin) from the chicken bursa of fabricius. Amino Acids 2011;40(2):505.

Li C, Chen A, Ding S, Zhao Y. Application of antibacterial peptides in broiler production. Feed Research 2008;(3):31-33.

Liu Y, Zang S, Li T, Yang J, Guo J, Zhao W. Effects of cinnamaldehyde on nutrient digestibility and intestinal microflora of broiler chickens. Chinese Journal of Animal Science 2013;49:65-68.

Ma Y, Gao Q, Ma S, Zhang J. Influence of luffa decoction on the immune function of mice. Chinese journal of traditional Chinese medicine 2015;30(9):1319-1321.

Michailidis G, Avdi M, Argiriou A. Transcriptional profiling of antimicrobial peptides avian beta-defensins in the chicken ovary during sexual maturation and in response to salmonella enteritidis infection. Research in Veterinary Science 2012;92(1):60-65

Mohamed S, Hashim SN, Rahman HA. Seaweeds: a sustainable functional food for complementary and alternative therapy. Trends in Food Science \& Technology 2012;23(2):83-96.

Nitschke U, Stengel D. A new HPLC method for the detection of iodine applied to natural samples of edible seaweeds and commercial seaweed food products. Food Chemistry 2015;172:326-334. 
Park S, Kim J, Yoe SM. Purification and characterization of a novel antibacterial peptide from black soldier fly (Hermetiaillucens) larvae. Developmental \& Comparative Immunology 2015;52(1):98-106.

Patterson J, Burkholder K. Application of prebiotics and probiotics in poultry production. Poultry Science 2003;82(4):627-631.

Radulovich R, Umanzor S, Cabrera R, Mata R. Tropical seaweeds for human food, their cultivation and its effect on biodiversity enrichment. Aquaculture 2015;436(1):40-46

Rajanbabu V, Chen JY. Applications of antimicrobial peptides from fish and perspectives for the future. Peptides 2011;32(2):415-420

Siahaan EA, Pendleton P, Woo HC, Chun BS. Brown seaweed (Saccharina japonica) as an edible natural delivery matrix for allyl isothiocyanate inhibiting food-borne bacteria. Food Chemistry 2014;152:11-17.

Virden W, Yeatman J, Barber S, Willeford K, Ward T, Fakler T, et al. Immune system and cardiac functions of progeny chicks from dams fed diets differing in zinc and manganese level and source. Poultry Science 2004;83(3):344-351

Wang J, Wu C, Feng J. Effect of dietary antibacterial peptide and zincmethionine on performance and serum biochemical parameters in piglets. Czech Journal of Animal Science 2011;56(1):30-36.
Wang M, Yang R, Zhang L, Meng X, Fei C, Zhang K, et al. Sulfated glucan can improve the immune efficacy of Newcastle disease vaccine in chicken. International Journal of Biological Macromolecules 2014;70:193-198.

Wang Q, Gao T, Chen Z. Seaweed powder feeding fattening pigs experiment. Shandong Journal of Animal Husbandry and Veterinary Science 2000;6:40.

Wang Z, Zhao H, Bayin C, He X. Application of roughcast cecropin to preventing and controlling diarrhea of weaned piglets. Chinese Journal of Xinjiang Agricultural Sciences 2007;6:824-827.

Wen L, He J. Dose-response effects of an antimicrobial peptide, a cecropin hybrid, on growth performance, nutrient utilisation, bacterial counts in the digesta and intestinal morphology in broilers. The British journal of nutrition 2012;108(10):1756-1763.

Wong K, Cheung PC. Nutritional evaluation of some subtropical red and green seaweeds part ii. In vitro protein digestibility and amino acid profiles of protein concentrates. Food Chemistry 2001;72(1):11-17.

Wu S, Zhang F, Huang Z, Liu H, Xie C, Zhang J, et al. Effects of the antimicrobial peptide cecropin ad on performance and intestinal health in weaned piglets challenged with Escherichia coli. Peptides 2012;35(2):225-230. 
